easily broken up, but others were very firm and had to be tied off. 'The bases of the tumors were transformed into masses of solid tissue, which were in places tied off and in others separated forcibly. The omentum was studded with metastutic deposits and the peritoneal surfaces roughened with small transparent bodies. Both tumors and a considerable portion of the omentum were removed. The patient did well for four days, took nourishment, had movements from the bowels, pulse and temperature satisfactory. On the fifth day there was a sudden rise of temperature, and the patient died in a few hours.

Dr. Mullory's report of the specimens is as follows :

"Two ovarian tumors, one larger than the other; the size of each mainly due to a large cyst which had been punctured. 'The two tumors were much alike in structure. lBesides the large cyst each contained a number of small cysts and masses of solid tissue. The iuner wall in places of the large and small cysts was covered with a delicate papillary growth, in some places one centimetre in depth. Microscopic examination of the solid tissue showed numerous glands lined with columnar epithelium, also in places solid masses of epithelium, many of the glands contuined small masses of hyaline material, and some were dilated into small cysts, with papillary masses projecting into them. 'The stroma was well marked, and consisted of fibrous tissue. 'The papillary masses on the wall of the large cyst showed a similar outgrowth of connective tissue covered with a columnar epithelium. On the base of the papillary masses were numerous glands. Several of the sinall cysts on the surface of the tumors had ruptured, and papillary masses projected out of them. 'The Fallopian tube on the larger tumor had two fimbriated openings. Attached to the larger tumor was a considerable portion of the omentum throughout which were disseminated muny small nodules from the size of a pin's head to a small marble. Examination of them showed them to be made up of glands and masses of epithelial cells similar to those in the more solid parts of the ovarian tumors, imbedded in a wellmarked connective stroma. Diagnosis, papillary adonocystoma of each ovary, with adeno-carcinomatous transformation, and metastasis in omentum."

Dr. Mallory further says that the transformation of a papillary adeno-cystoma into a malignant growth is not very common, although well-known to occur.

The other case, which was operated on within a week of this one, had the same papillary growths and the same solid masses at the base and I should not have been at all surprised to learn that it, too, was malignant, but no such change was found.

A word or two in closing as to prophylaxis. In the case of abdominal tumors, operate early. Such a case as the last reported might have been saved had the patient consented to operation when the tumor was first discovered. In the case of hemorrhage from the uterus, curette, subject the scrapings to the microscope and at the first return of symptoms curette again and get mucosa into a healthy condition if possible, but if the bemorrhage recurs even though the microscope fails to detect malignancy, be on the side of radicalism, and remove the uterus.

As regards cancer of the vaginal portion, especially epithelioma, I believe lacerations of the cervix stand in a certain causal rolation. I would, therefore, on that ground alone, even in the absence of other symptoms referable to the lesion, urge the repair of all lacera- tions of the cervix which present themselves. I believe if this practice could be carried out, the number of cases of cancer would diminish. Finally, I would emphasize the duty of the profession to examine early all cases of irregular hemorrhage or foul discharge, that if malignant disease be present they may be operated on immediately.

\section{ENURESIS IN CHILDREN. ${ }^{1}$}

BY IAROLD WHLLAMA, M.L.

Professor of Diseases of Children, 'Tufts College Medical School.

In looking over my notes for something to present to your attention this evening I find that in the past five years $I$ have treated 62 cases of nocturnal enuresis in children, a number which is certainly sufficiently large to apologize for my directing your notice to this troublesome affection. It is, moreover, a source of surprise to me to see how lightly this subject is dismissed by most of our modern authors. Suchs, for example, in his treatise on the nervous diseases of children, in spite of the fact that the infirmity is now classed among the neuroses, disposes of the whole question in a single page in which $I$ find the assertion that: "Many medical men have seriously suggested that corporal punishment applied to the nates is the only efficient remedy . . . but . . . it is very cortain that such punishment need not be inflicted in the majority of cases." 'The relative frequency of the infirmity and the slight notice it has attracted are my reasons for bringing this subject to your notice this evening.

Of the 62 cases included in my notes, 34 were in girls and 28 were in boys, thus showing that $80 x$ does not play an important part in its causation. The ages of the patients were as follows:

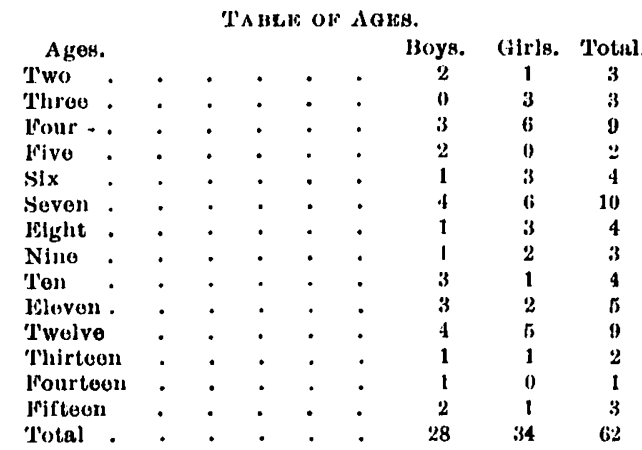

From this table we aguin see that age does not seem to be a particularly important factor, though in this context it is interesting to note that while Dr. Rotch, in his new book on pediatrics, in the two pages devoted to this affection says: "The cases in which enuresis does not disappear at puberty are nearly slways in girls," we find that in the fifteen cases in the table occurring after the twelfth year rather more than 50 per cent. occurred in boys.

In 13 of the cases a definite cause of reflex irritation was detected and corrected, in 12 with a cessation of the enuresis. 'These causes were as follows: Adherent prepuce, four cases; vulvo-vaginitis, with gonococci, one case; oxyuris vermicularies, five cases; chronic ileo-colitis, one case; prolapse of the rectum, 
one case. A condition of anemia and a neurotic temperament and history were noticed in a large but unrecorded number of the children. A balance of fortynine cases remain in which the cause is unexplained.

In the Archives of Pediatrics for November, 1893, Dr. B. K. Rachford has contributed a most complete and exhaustive essay upon this subject. He regurds the incontinence of urine in children as a true neurosis, and, like other neuroses in children, as made up of " a tripod of etiological factors, namely, (1) irritable and unstable nerve centres, (2) anemia with consequent mal-nutrition, (3) reflex stimulation of certain nerve centres in the lumbar cord." In his article, the mechanism of micturition is explained by allusion to von Zeissl's rescarches on the innervation of the bladder, which I cannot recall to your minds more clearly or concisoly than in Dr. Rachford's own words: "He found (von Zeissl) that the 'erector nerve' was not only the motor nerve of the muscular coat of the bladder, but that it was also the inlribitory nervo of the sphincter vesica, and that the 'hypogastric nerves' carry motor fibres to the sphincter vesicie and inhibitory fibres to the muscular cont of the bladder itself. These researches of von Zeissl make plain the manner in which reflex causes may act in starting or checking the flow of urine. For example, a reflex carried to the proper centre in the lumbar cord would, through the motor fibres of the erector nerve, contract the muscular cont of the bladder, and through tho inhibitory fibres of the same nerve relax the sphincter vesica, and in this manner allow the urine which is being expelled by the contracting bladder to pass with. out hinderance through the relaxed sphincter vesicas."

After going on to speak of the part played by the will in hindering or causing the passage of the urine, Dr. Rachford says that the causes which produce incontinence must act in two ways: First, directly on the centres in the lumbar cord making them more irritable or unstable, and in that way exciting their reflex irritability. Second, indirectly through exaggerated reflex causes that influence both accelerator and inhibitory influences sent to the bladder; these influences may be psychic, originating in the bruin, or they may be the result of extermal irritation originating in or near the bladder itself."

This admirable paper sums up with these conclusions: "There are three important etiological factors of incontinence of urine in children, namely : First, excitability of the nerve centres produced by horedity and age; second, anomia or mal-nutrition, increasing the excitability of the nerve centres; third, reflex irritation. 'These factors are interdependent and act together in producing this condition."

Up to this point I have nothing to add to what has been said by Dr. Rachford. My experience closely coincides with what he has written, and I believe he has done much toward elucidating one of the most perplexing of the disorders of childhood.

I am disposed, however, to emphasize more strougly than Dr. Rachford has done another factor, namely, the control which is exerted by the higher over the lower centres - the influence exerted by the brain. Pursuing the method of Dr. Ruchford, I would state that according to Coulton, there are fibres in the columus of the cord connecting the lumbar centres through the cerebral peduncle with the brain, and through these fibres the influence of the brain is felt; this being the mechanism of the familiar fact that after the first year of life the act of urination is largely governed by the will.

'To the three etiological factors of Rachford's, which I would take the liberty of slightly modifying, I would therefore add those cases of enuresis caused, at least in part, by

(d) Direct volition,

(e) Auto-suggestion,

(f) Retarded mental development,

(g) Enfeeblement of the will.

But before wo consider these seven factors in detail allusion should be made to local organic causes, such as malformations, fistula, polypoid excrescences of the neck of the bladder, traumatism, etc., without allusion to which any classification would be manifestly imperfect.

All cases of enuresis must, therefore, be divided into two classes :

(1) Those of local organic origin, such as malform. ations, etc., and

(2) 'Those of functional origin, in which the function of the bladder is interfered with in consequence of functional or organic disease of other organs.

These cases of functional origin I regard as due to seven factors, one or more of which are probably present in every case.

(a) Undue excitability of the spinal centres is a factor which is probably present in a large majority of cases. It is, therefore, of importance to make careful inquiry into such possible causes as may augment the condition: namely, stimulating articles of diet, such as strongly albuminous food, tea, coffee, condiments and spices. Hygienic causes, such as sleeping on the back, stimulating plays, and the bad practice of tickling children must be thought of. Vicious habits, wuch as iudulgence in tobacco, alcohol and masturbation wust be considered. In this context I would say that Jacobi may be cited as an authority for the frequency of this last cause [Kenting].

(b) Anomia. Dr. Rachford believes anemin to be a most important factor. In the article from which I have so freely quoted he says: "Over one-half the cases of incontinence of urine seen in dispensary practice at Cincinnati, $O$., have a tubercular anemia; about fifteen per cent. have rheumatic anomia, and a smaller percentage have malarial and syphilitic anemia." Judging from my own cases this is all over-statement, though anemia is undoubtedly an important factor in many cases. But as we all know, anemia exists without enuresis, and in private practice it is rarely found associated with the neurosis under consideration. Furthermore, when the two are coexistent it is imposble to say that either is the cause of the other or that both are not dependent upou some common cause, as, for example, masturbation. But when an anemic condition existed in the 62 cases it was often treated with uratifying results. Under such circumstances I have been accustomed to prescribe the tinct. ferri chlorid. in an emulsion of cod-liver oil; and Wyeth's elixir of gentian et tinct. ferri chlorid. has been the form preferred.

(c) Reflex irritation, as we have seen, is an important causative factor, such causes boing detected in 13 out of the 61 cases. But it must bo remembered that it is only a factor; not all cases of alherent prepuce, prolapse of the rectum, distention of the bladder, etc., lead to enuresis, and the physician must not be satisfied by removing this cause alone. Other causes are asso- 
ciated and allied, and these other causes "must come in for our consideration and treatment. Furthermore, it wust not be lost sight of that causes of reflex irritation may exist though undiscovered by the physician; and he will be most successful in his treatment of such cases who makes the most careful investigation into these possible reflex irritants.

(d) Direct volition is a factor which must be regarded as present in some of the cases. The child awakes with the desire to micturate, but does not get up to do so because of unwillingness to rouse itself sufficiently, because it is afraid of the dark, because it is cold, or for some similar reason, preferring to wet the bed to subjecting itself to the discomfort of getting out of it. Or it may be an act of direct wilfulness, which latter would belong to the class of cases alluded to by Sachs in which "many practitioners advise punishment."

(e) Auto-suggestion, I believe, also played an important rôle in some of my cases. For some reason or other, the habit once instituted is continued by auto-suggestion. A child who wets the bed is scolded, ridiculed, or maybe punished for it, and it assumes immense and exaggerated importance to his mind. $\mathrm{He}$ is constantly thinking of it and wondering about it until the fear of it becomes a fixed idea. To such a case the apprehension leads to auto-suggestion and enuresis follows. In this class probably belong the cases mentioned by Bernheim, ${ }^{2}$ in which a boy of thirteen and a boy of seventeen were cured by hypnotism, each in a single séance; by Liebault, of a girl of eight cured by hypnotism, and by Albert Moll. ${ }^{8}$ Goodhart, in his "Diseuses of Children," speaks of "a form of nocturnal incontinence which replaces the seminal emissions of the mature organism." Such cases I regard as automatic, and include in this class. I have now under my care a man who is troubled by diurnal incontinence of urine which is unmistakably due to auto-suggestion, and I am further inclined to the belief that auto-suggestion explains the eflicacy of many of the vaunted remedies.

$(f)$ Of retarded mental development nothing need be said. It is merely necessary to bear in mind that the norve supply of the bladder is only slightly developed during the first one or two years of life, and that this condition may persist longer through retarded development.

(g) Enfeeblement of the will is a factor of more serious importance and of more frequent occurrence than is probably generally recognized. Inhibitory impulses are conveyed from the brain to the spinal centres, and these restraining impulses are undoubtedly operative during sleep. Any cause which may lead to enfeeblement of these centres may lead to nocturnal incontinence, in which cuse it may be a symptom of grave import - a warning note, which if properly interpreted, may ellable us to inaugurate such a system of hygienic education as will ward off some of the neurasthenias and hysterias of adult life. Such an hypothesis is difficult of proof, yet it has occurred twice in my own experience; once in the youth of a young woman who has suffered from neurasthenia, and once in a child who was subsequently hysterical. I find mention of youthful enuresis in the history of one of Krafft-Ebing's cases - an instance of grave mental disturbance occurring in an adult male; and Dr. $S$.

\footnotetext{
Suggestlve Therapeuties, pp. 360 and 351.
}

G. Webber writes me, "I have had several cases of neurasthenia where there was nocturnal incontinence in childhood." I)r. R. 'T. Edes, in answer to an inquiry of mine, mentions the cases of two persons in his experience in whom this symptom occurred; one of whom is "not a neurasthenic in the ordinary sense, but lacking in certain mental attributes, and the other who is peculiar and of deficient intelligence." 'This last factor I offer as a suggestion which experience may prove to be of future utility.

Nocturnal incontinence is therefore to be regarded as a symptom, varying in degree from a simple indication of the naughtiness of a wilful child to the precursory warning of subsequent nervous deficiency, and the treatment of the condition requires careful study into the causation of each particular case. No case should be lightly dismissed as of trivial importance until such careful investigation has been made. When tonic treatment is indicated, I regard the iodide of potush as an extremely valuable remedy. Personally, I have seen no benefit derived from raising the foot of the bed.

\section{Elinital gDepartment.}

\section{A CASE OF CERVICAL, RIB, WI'TH OPERA'TION. ${ }^{1}$}

\author{
ISY J. COLLINA WARIRN, M.D., LL.D., \\ I'rofessor of Suryery in IIarvard University.
}

Mrs. 13., thirty-five years of age, is tall and thin and has enjoyed good health. Has had two children. For a number of years has supposed she had rheumatisin in her shoulder, and for two or three years much pain. The principal pain is at about the middle of the right clavicle, extending down the arm and sometimes reaching the lower end of the nlna. Of late the power of the arm seems to have diminished, and the pain has increased so that she is frequently prevented from sleeping at night.

On examination a bony tumor is observed behind the middle of the right clavicle, arising apparently from the first rib; overlying it is a large artery which at times appears to give a sensation of pulsation to the whole tumor. The outer border of the tumor is particularly sensitive, on the opposite side of the neck a similar bony prominence is felt, but it is much smaller.

A large rectangular flap was turned up, uncovering the whole region of the tumor, and ufter the fuscia was incised a bony mass was observed upon which lay upon the inside the subclavian artery and on the outside the brachial plexus. On further dissection the bony mass was found to be a rib articulating with the first rib by a facet situated a short distance behind the insertion of the scalenus anticus. 'The scalenus medius was inserted into the cervical rib. This rib was disarticulated and removed piecemeal, nearly up to the point of its origin from the seventh cervical vertebra.

'The romoval of the bone seemed to relax the brachial plexus which had been somewhat stretchod by the the arching position of the bone. 'The wound healed by first intention and the patient has experienced little or no pain since and is recovering the use of the urm.

[The pationt was shown at the meeting, about two months after the operation, and expressed herself 1 Lend at the flrst Clinteal Meoting of the Medloal Bonrd of the
Massachusotta Goneral Hospital, December 16, 1806 . 